\title{
ON THE TESTABILITY OF THEORIES OF
}

\section{LANGUAGE EVOLUTION}

\author{
Rudolf P Botha \\ Department of General Linguistics, University of Stellenbosch, \\ Stellenbosch, South Africa*
}

\section{Introduction}

Theories of the evolution of human language express by their very nature claims of a historical sort: claims about why, when, where or how language emerged and/or developed in some distant past.' An essential feature of these claims is that they are made in the absence of sufficient historical evidence about the evolutionary events, biological processes, physical forces, environmental pressures, kinds of (pre)linguistic entities and so on involved in the evolution of language. The paucity of this historical evidence - i.e., evidence derived from data contained in natural or man-made records of these evolutionary events etc. - is generally seen as one of the most formidable obstacles to serious work on language evolution. ${ }^{2}$

The paucity of historical evidence about the evolution of language has given rise to a kind of speculation on language evolution which has long been considered scientifically unrespectable. Thus, in 1873, the eminent American philologist William Whitney depreciatingly characterized such speculation as

"... mere windy talk, the assertion of subjective views which commend themselves to no mind save the one that produces them, and which are apt to be offered with a confidence, and defended with a tenacity, that are in inverse ratio to their acceptableness. This has given the whole question a bad repute among sober-minded philologists". (Whitney, 1873 , p. 279).

And, in the same year, Alexander Ellis, the then president of the Philological Society of London, declared:

"We [philologists - R.P.B.] shall do more by tracing the historical growth of one single work-a-day tongue, than by filling wastepaper baskets with reams of paper covered with speculations on the origin of all tongues." 
Even earlier, in 1865, the Sociéte de Linguistique de Paris adopted a bylaw, Article 11, which placed a (publication) ban on work on the origin of language:

"The Society will accept no communication dealing with either the origin of language or the creation of a universal language."

Nearly a century and a half later, evidential paucity is still regularly singled out as a fundamental limitation on serious work on language evolution. Thus, commenting critically on Steven Pinker and Paul Bloom's (1990) adaptationist account of language evolution, Richard Lewontin (1990, p. 741) observes that they "do not and often cannot know the basic facts on which [their] theory [in principle - R.P.B.] rests." ${ }^{5}$ In similar vein, Massimo Piattelli-Palmarini (1990, p. 574) critically remarks that Pinker and Bloom's "case" would of necessity have to rest on data that are "impossible to collect." And, to mention one more example, in the context of defending their "evolutionary scenario for the emergence of the neural preconditions for language in the hominid lineage", Wendy Wilkins and Jennie Wakefield (1995, p. 219) observe that, since there generally is "such a tremendous lack of evidence" of a historical sort, it does not seem "particularly productive .... to speculate on why things did not happen differently" in the emergence of language. They (1995, p. 165) emphasize the fact, moreover, that in particular there is "an extreme paucity of appropriate material" bearing on changes in brain size and brain organization in evolution. In their (1995, p. 219) view, one of the (few) things about which "all interested researchers can probably agree is that the fossil record is not very revealing about the evolution of higher cognitive function", the fossil record being considered a major source of historical data about language evolution.

In recent work on the evolution of language, however, interesting attempts have been made to overcome the problem of evidential paucity and, in Pinker and Bloom's (1990, p. 727) words, to counter the "[s]kepticism about the possibility of saying anything of scientific value about language evolution." Central to attempts at countering this skepticism has been the adoption of a condition of testability for theories of language evolution. An appraisal of the progress that has been made in work on language evolution, accordingly, requires amongst other things a critical analysis of this condition as it has featured in this work ${ }^{6}$. To offer such an analysis is the main 
aim of the present article. This analysis will focus on work that is or could be claimed to be informed by knowledge both of theoretical linguistics and of evolutionary biology in addressing questions such as the following:

(1)(a) What were the preconditions for language and how did they emerge?

(b) What was/were the precursor/precursors of language?

(c) In the first entity/collection of entities that may be justly called "language" (henceforth: "ancestral language" for short), which of the initial functions was/were the evolutionary pertinent one(s)?

(d) What were the formal features of ancestral language and how were these interlinked with the function/functions referred to in (c) above?

(e) In the evolution of language, what were the major phases?

(f) What were the biological processes, physical forces, and environmental pressures causally involved in each of the phases referred to in (e) above?

(g) Did language evolve in (i) a gradual or abrupt way or (ii) a continuous or discontinuous way?

The genre of work on language evolution which, in pursuing questions such as (1)(a) - (g), is or could be claimed to be informed to some extent by knowledge of both theoretical linguistics and evolutionary biology, I will refer to below, for convenience, as "work in evolutionary linguistics. ${ }^{77}$ In analysing such work, I will focus in this article on a number of contributions that deserve to be considered among the more sophisticated ones, including (Pinker and Bloom, 1990), (Wilkins and Wakefield, 1995) and (Hurford, Studdert-Kennedy and Knight (eds.), $1998)^{8}$

\section{Testability in evolutionary linguistics}

Even scholars who differ strongly on what the evolution of language involved agree at a metalevel that the persistent doubts about the scientific respectability of theories of this process can be countered by adopting a condition which in essence one may state as follows: 
(2) Theories of the evolution of language have to be testable. ${ }^{9}$

Theories which fail (a version of) this testability condition are dismissed as "empty", "unscientific" and so on. Before turning to what is problematic about condition (2), it is necessary, however, to dispel any doubts about the weight this condition has been accorded in the epistemology of evolutionary linguistics.

In propounding their adaptationist theory of language evolution, Pinker and Bloom (1990) deliberately attempt to address "the set of methodological worries lurking behind people's suspicions of natural selection":

"Isn't adaptationism fundamentally untestable, hence unscientific, because adaptive stories are so easy to come by that when one fails, another can always be substituted?" (Pinker and Bloom, 1990, p. 711).

Judging these "worries" unfounded, however, they go on to assert that

"... specific adaptationist proposals are testable in principle and practice ..." (Pinker and Bloom, 1990, p. 711).

Pinker and Bloom, moreover, invoke condition (2) in contending that

"... it is nonadaptationist accounts that are often in grave danger of vacuity. Specific adaptationist proposals may be unmotivated, but they are within the realm of biological and physical understanding, and often the problem is simply that we lack the evidence to determine which account within a set of alternative adaptive explanations is the correct one. Nonadaptationist accounts that merely suggest the possibility that there is some hitherto-unknown law of physics or constraint on form - a 'law of eye-formation', to take a caricatured example - are, in contrast, empty and nonfalsifiable." (Pinker and Bloom, 1990, p. 711).

Significantly, though their adaptationist theory of language evolution is extensively criticized in the BBS discussion, not one of their critics questions the importance accorded by Pinker and Bloom to the testability condition. Indeed, some of these critics, in criticizing Pinker and Bloom's theory, invoke (a version of) the condition themselves. For example, Piattelli-Palmarini 
(1990) charges that it is impossible to "refute" or even to "substantially weaken" the "adaptationist hypotheses" offered by Pinker and Bloom because

"... they manage to render their approach utterly indefeasible (this is not meant to be a compliment) ..." (Piattelli-Palmarini, 1990, p. 754).

And he goes on to level the following charge at Pinker and Bloom:

"Resting their case on data that their own approach would have made impossible to collect .... they proceed to construct an a posteriori, ad hoc, irrefutable explanation." (Piattelli-Palmarini, 1990, p. 574).

A similar, important status is accorded to a testability condition by participants in the recently held Edinburgh conference on approaches to the evolution of human language. Thus Robin Dunbar (1998) asserts:

"Our understanding of processes like language will grow only by being challenged in this way, but it will do so only providing that we resort to empirical testing of competing hypotheses. Armchair speculation has been all too characteristic of this debate in the past." (Dunbar, 1998, p. 106).

Referring to the hypothesis that genetic resources "freed up" from selection can "carve out" new functional domains, Robert Berwick (1998), in turn, observes:

"To be sure, such a scenario for evolutionary innovation is speculative, but it is at least one that can be tested and is currently being tested in living organisms (...)" (Berwick, 1998 , p. 338).

And in support of "arguments" to the effect that language is linked to the evolution of social intelligence, Camilla Power claims:

"They [i.e., 'those arguments' - R.P.B.] can yield hypotheses which are testable not only through observation of modern behaviour .... but potentially by using data from the paleontological, archaeological and ethnographic records ...." (Power, 1998, p. 111).

In arguing in a BBS discussion for his frame/content theory of the evolution of speech production, Peter MacNeilage (1998, p. 509) asks "ls this theory testable?" And he goes on to answer this question by listing various "predictions" which, in his view, can be "tested". 
Interestingly, in a review of Mark Ridley's book The Origin of Virtue, Sulloway (1998) takes this condition to embody an "enduring Darwinian virtue":

"As Charles Darwin taught more than a century ago, openness to diverse lines of evidence and a dogged dedication to hypothesis testing are enduring Darwinian virtues." (Sulloway, 1998, p. 40).

In one formulation or another, the testability condition (2) is clearly central to the epistemology of work that has recently been done in evolutionary linguistics. ${ }^{10}$ This condition is problematic in various ways, however, since its proponents have neglected to make clear what exactly testability (or "falsifiability" or "refutability" etc.) involves. In particular, they have not explicitly considered the factors that are harmful to the testability of individual hypotheses or of theories as structured collections of hypotheses. " Consequently it is on the whole unclear whether a particular hypothesis or theory is as testable or as untestable, as it has been made out to be by its defenders or critics, respectively. So let us consider the major factors that have conventionally been taken to harm or undermine the testability of hypotheses or theories and determine to what extent these factors affect the testability of hypotheses about or theories of language evolution. In doing this, we will find it necessary to take into account the distinction between testability-in-principle and testability-in-practice. ${ }^{12}$ For convenience, the term "theory" will be used as an abbreviation of "theory or hypothesis" where appropriate in the context.

\section{Ontological transparency .}

To be testable-in-principle, a theory $\mathrm{T}$ has to meet the following condition of ontological transparency:

(3) It must be possible to identify in a non-arbitrary way the entity or entities about which $T$ expresses one or more claims.

If this entity/these entities cannot be identified non-arbitrarily, then evidently the claim/claims expressed by $T$ will be unclear in regard to content. And, consequently, this claim/these claims will be impossible to test, since it/they will lack precise test-implications which can be confronted with relevant evidence. A theory that fails condition (3) can be said to suffer from ontological opacity, making it untestable-in-principle. 
Now, even relatively sophisticated theories of language evolution fail the condition of ontological transparency in one or more of three ways:

(4)(a) It is unclear what the entity is/entities are about whose evolution these theories express claims (or are intended to express claims).

(b) It is unclear whether these theories express claims (or are intended to express claims) about the evolution of this entity as a whole/these entities as wholes or about some or all individual traits of this entity/these entities.

(c) It is unclear about what phases in the evolution of the entity/entities these theories express claims (or are intended to express claims).

Let us consider each of these three ways in turn, as they are illustrated (a) by the BBS discussion of Pinker and Bloom's (1990) selectionist theory of language evolution, and (b) by various contributions to the Edinburgh conference (Hurford, Studdert-Kennedy and Knight (eds.), 1998) of approaches to the evolution of language.

\subsection{Identity of the linguistic entity/entities}

Pinker and Bloom (1990) use a variety of expressions for referring to the linguistic entity/entities of whose evolution their selectionist theory offers an account. Here are some examples (all emphases added - R.P.B.):

\section{- language}

"We will argue that there is every reason to believe that language has been shaped by natural selection as it is understood within the orthodox 'synthetic' or 'neo-Darwinian' theory of evolution (...). In one sense our goal is incredibly boring. All we argue is that language is no different from other complex abilities such as echolocation or stereopsis, and that the only way to explain the origin of such abilities is through the theory of natural selection." (Pinker and Bloom, 1990, p. 708).

- the (human) language faculty

"In the evolution of the language faculty, many 'arbitrary' constraints may have been selected simply because they defined parts of a standardized communicative code." (Pinker and Bloom, 1990, p. 718). ${ }^{13}$ 
- the language acquisition device

"More generally, these considerations suggest that a preference for arbitrariness is built into the language acquisition device at two levels." (Pinker and Bloom, 1990, p. 718).

- universal grammar

"Does universal grammar in fact show signs of adaptive complexity?" (Pinker and Bloom, 1990, p. 773).

- $\operatorname{grammar}(\mathbf{s})$

"Evolutionary theory offers clear criteria for when a trait should be attributed to natural selection : complex design for some function, and the absence of alternative processes capable of explaining such complexity. Human language meets these criteria: Grammar is a complex mechanism tailored to the transmission of propositional structures through a serial interface." (Pinker and Bloom, 1990, p. 707). ${ }^{14}$

- the cognitive mechanisms underlying language

"Do the cognitive mechanisms underlying language show signs of design for some function in the same way that the anatomical structures of the eye show signs of design for the purpose of vision?" (Pinker and Bloom, 1990, p. 712).

- the computational mechanisms underlying the psychology of language

"Our own arguments spring from the adaptive complexity of the computational mechanisms underlying the psychology of language as it is currently understood." (Pinker and Bloom, 1990, p. 766).

Pinker and Bloom's use of the expressions exemplified above naturally gives rise to questions about the identity of the linguistic entity/entities for whose evolution they are offering a selectionist account. Do the authors intend these different expressions to refer to different entities? Or do they intend all these various expressions to refer to one and the same entity? If so, what is this entity? For instance, is the entity referred to here by the expression language the same as the entity referred to by the expression the cognitive mechanisms underlying language or by the expression the computational mechanisms underlying the psychology of language? Are an entity and the mechanisms underlying it the same thing? Are language and the psychology of language the same entity? Pinker and Bloom nowhere address questions such as these explicitly 
— an omission that leaves a significant measure of ontological opacity in their selectionist theory.

Consider next Pinker and Bloom's use of the expressions the (human) language faculty, the language acquisition device, universal grammar and grammar. Within an orthodox generativist ontology, these expressions may be taken to refer to the entity that Chomsky calls "the initial state of the language faculty." But what is the entity to which Pinker and Bloom refer by means of the expression (human) language. Is that entity also the initial state of the Chomskyan language faculty? Or is it an entity distinct from the initial state of this faculty? This gives rise to the question whether provision is made within an orthodox generativist linguistic ontology for two distinct entities, namely language and the (initial state of the) language faculty. Specifically, within this ontology, what would language be as something distinct from the initial state of the language faculty? Chomsky has dealt with these questions in a tangential way only. His position seems to be that, within a generativist ontology, there is no factual basis for distinguishing between the initial state of the language faculty and language as a distinct entity abstracted from this state. Consequently, as used by Chomsky, the expressions language and the initial state of the language faculty refer to one and the same linguistic entity. ${ }^{15}$

The question, of course, is whether Pinker and Bloom subscribe to Chomsky's identification of language with the initial state of the language faculty. And whether they consequently use the expressions (human) language and the language faculty as synonyms to denote the linguistic entity whose evolution is at issue. Their BBS article has passages in which they switch between these two expressions freely, seemingly treating them as synonyms, passages such as the following [all emphases added - R.P.B.].

"Many people have argued that the evolution of the human language faculty cannot be explained by Darwinian natural selection. Chomsky and Gould have suggested that language may have evolved as the by-product of selection of other abilities or as a consequence of as-yet unknown laws of growth and form." (Pinker and Bloom, 1990, p. 707). 
"In the evolution of the language faculty, many 'arbitrary' constraints may have been selected simply because they defined parts of a standardized communicative code in the brains of some critical mass of speakers. Piattelli-Palmarini may be right in claiming that there is nothing adaptive about forming yes-no questions by inverting the subject and auxiliary as opposed to reversing the order of words in the sentence. But given that language must do one or the other, it is highly adaptive for each member of a community of speakers to be forced to learn to do it in the same way as all the other members." (Pinker and Bloom, 1990, p. 718).

Passages such as these seem to suggest that, within Pinker and Bloom's linguistic ontology, language and the (human) language faculty are one and the same entity. And yet, in responding in the BBS discussion to criticisms by Dan Sperber (1990) and by Anat Ninio (1990) to the effect that they have not explicitly taken into account the distinction between language and the language faculty, Pinker and Bloom seem to be saying that they do consider language and the language faculty to be distinct entities. ${ }^{16}$ Thus, lumping Sperber's and Ninio's criticisms together, Pinker and Bloom reject the "suggestions" of both:

"Contrary to the suggestions of Ninio and Sperber, there are no paradoxes, or confusions between language and the language faculty ...." (Pinker and Bloom, 1990, p. 776 - 777).

The 'argument' to which they refer concerns involving the Baldwin effect in explaining how innate grammatical mechanisms might have developed gradually from communication systems which were originally supported by general cognitive processes. The reason why there are no such confusions or paradoxes, according to Pinker and Bloom, is that:

"If some people are using a grammatical construction (either because of a special genetic property or general cognitive talents), there could be an advantage in others' evolving to be able to process it automatically, with dedicated hardware, as opposed to conscious inferential reasoning ... Moreover, a genetic change in the language faculty need not simply generate the ambient language verbatim in which case ease of processing would be the only selection pressure, and further evolution would halt. It can generate a superset of the language (or a partially overlapping set), much the way contemporary children go beyond the information given in the development of creoles, sign languages, and their frequent creative inventions. If such creations increased expressive power and were comprehendable by others by any means, it could set the stage for the next iteration of the evolution process." (Pinker and Bloom, 1990, p. 776). 
What is interesting about this response is that Pinker and Bloom do not argue that the distinction between "language" and "the language faculty" invoked by Sperber and by Ninio is purely terminological, or obscure, or flawed in some other way. Moreover, Pinker and Bloom seem to agree in principle that "language" and "the language faculty" could be confused as the explanatory target of a selectionist account in a way that would reflect negatively on such an account. Yet they refrain from drawing the distinction between "language" and "the language faculty" in an explicit way within a clearly articulated linguistic ontology. Moreover, they introduce the notion of "the ambient language" into the discussion, without explicitly clarifying its ontological import vis-á-vis that of the concepts of "language" and "the language faculty". As a consequence, the claims expressed by Pinker and Bloom's theory about the evolution of "language" are ontologically opaque, hence untestable-in-principle. ${ }^{17}$

To ensure, then, that claims expressed about the evolution of "language" are testable-in-principle, the linguistic entity or entities whose evolution is at issue should be identified in a clear and nonarbitrary way. Scholars working in evolutionary linguistics generally seem to agree, on the face of it, that the entity whose evolution is at issue is "language". But on closer inspection, this agreement turns out to be more apparent than real, since different scholars often proceed from ontologically distinct conceptions of the entity they refer to as language. Then, too, there are those who hold ontologically distinct conceptions of "language", invoking in a non-deliberate way now one and then another. For example, in the Edinburgh discussion, the term language is used in the senses illustrated below, amongst others [all emphases added - R.P.B.].

- Aitchison:

(i) "Language, like many other aspects of human behaviour, is a case of 'mosaic' evolution ...." (Aitchison, 1998, p. 19).

- Donald:

(i) " ... language is too broad a process ....." (Donald, 1998, p. 46).

(ii) ".... language is really a gigantic meta-task ...." (Donald, 1998, p. 56). 
(iii) "The acquisition of any special human skill, including language ..." (Donald, 1998, p. 58).

- Dunbar:

(i) "... the function of language (as an activity) is to ...." (Dunbar, 1998, p. 107).

- Studdert-Kennedy, Knight, Hurford:

(i) However, historical changes within, and divergences among, languages are largely cultural matters, biologically constrained, no doubt, but quite distinct from the evolution of language as, a species-specific capacity." (Studdert-Kennedy, Knight, Hurford, (eds.), 1998, p. 2).

(ii) "What we need therefore is an account of language evolution, sensitive both to language as 'a sort of contract signed by members of a community' and to language as hard-wired (individual) competence generated under standard processes of Darwinian natural selection." (Studdert-Kennedy, Knight, Hurford (eds.), 1998, p. 2).

(iii) "We need to place language among those many group behaviours of social animals from the reproductive processes of eusocial insects to the hunting routines of a wolf pack - that can only emerge through interactions among individuals." (StuddertKennedy, Knight, Hurford (eds.), 1998, p. 2).

- Worden:

(i) "Social intelligence and a theory of mind are vital pre-requisites for language. 1 propose that language is not just a new mental faculty which uses these two, but a direct application of them." (Worden, 1998, p. 149).

Characterizing language in the ways exemplified above gives rise to various crucial questions: About the evolution of what entity or entities are the scholars in question expressing claims? How could these claims be at one and the same time claims about an "aspect of human behaviour", a "process", a "meta-task", a "special human skill", an "activity", an "application of social intelligence and a theory of mind", a "species-specific capacity", a "sort of contract signed by members of a community", "hard-wired (individual) competence", and a "group behaviour"? Given the obscurity in import of claims about the evolution of "language" that are stated in terms of such ontologically non-identical expressions, how could these claims be testable-in-principle? 


\subsection{Entities as wholes $v s$. the traits of entities}

A theory of the evolution of some linguistic entity cannot satisfy the ontological transparency condition (3) unless it is clear whether this theory is a theory of the evolution of this entity as a whole or a theory of the evolution of (certain) individual traits or characteristics of the entity. Considered from this perspective, Pinker and Bloom's selectionist theory is problematical. Thus, taking this theory to offer an account of the evolution of the (initial state of the) language faculty, Elliot Sober poses in the BBS discussion the following problem to both critics and defenders of Pinker and Bloom's theory:

"The subject at hand is whether 'the human language faculty' can be explained by Darwinian natural selection. Both sides will be happy to grant that 'the human language faculty' has a multiplicity of characteristics. How much of a dispute would remain if this single question about the evolution of a univocal object - 'the human language faculty' were replaced by a set of questions, each of them focusing on a different characteristic of the human language faculty?" (Sober, 1990, p. 764). ${ }^{18}$

Now, Pinker and Bloom vacillate between portraying their selectionist theory as a theory of the evolution of language/the language faculty as a univocal object and depicting it as a theory of the evolution of individual characteristics of language/the language faculty. In certain passages of their target article, they distinguish some characteristics (or "parts") of the language faculty from others. Thus, they $(1990$, p. 718$)$ assert that if one "part of language" has no function, this does not mean that all "parts of language" have no function. ${ }^{19}$. And, in response to certain peer criticisms, Pinker and Bloom (1990, p. 765) declare that from the viewpoint of a theory of language evolution that assigns a central role to adaptation, the ubiquity of "arbitrary aspects of even the most obvious adaptations" is irrelevant. From these and similar other remarks by Pinker and Bloom, their selectionist theory seems not to be a theory of the evolution of the language faculty as a whole. In other passages, however, they remark on language/the language faculty as if it evolved as a univocal object. They make assertions such as the following, for instance [emphases added - R.P.B.]:

"The way to explain the evolution of language may not be to look for some climatic or ecological condition to which it was a direct selective response." (Pinker and Bloom, 1990, p. 773). 
In short, Pinker and Bloom leave it unclear whether their selectionist theory should be testable as a theory of a univocal object or as a theory of (a subset of) individual characteristics of an object. And they make no attempt to delimit the membership of this subset. Nor do they consider questions such as the following: If their selectionist theory were a theory of the evolution of a univocal object, under what conditions would it be proper to consider it true or false? Claims about what characteristics of this object have to be tested and falsified for the theory to be false as a theory about an univocal object? These are crucial questions, for, as Sober observes:

"An overall assessment of whether the entirety of this [univocal - R.P.B.] structure is 'mainly' due to natural selection cannot be obtained without this sort of attention to details ('parts')." (Sober, 1990, p. 764).

The "parts" referred to here by Sober are those that differ in regard to functionlessness.

Scholars adopting a selectionist stance on the evolution of language have so far failed to address the question of just how detailed this "attention to parts" has to be. In this connection, David Pesetsky and Ned Block (1990) draw a tripartite distinction between three "degrees of adaptationism" in their BBS commentary on Pinker and Bloom's selectionist theory:

- Lunatic adaptationism

"The view that every feature of a system was shaped by natural selection." (Pesetsky and Block, 1990, p. 751).

- Extreme adaptationism

"The view that every feature of a system that an engineer might regard as a design feature was shaped by natural selection." (Pesetsky and Block, 1990, p. 751).

- Strong adaptationism

"The view that many of the most salient of the features of a system that an engineer might regard as design features were shaped by natural selection." (Pesetsky and Block, 1990, p. 751).

This distinction offers Pinker and Bloom a framework for clarifying the ontological import of their selectionist theory. But they $(1990$, p. 760$)$ use it in a limited way only, namely by agreeing with Pesetsky and Block that the view embodied in "lunatic adaptationism" should be rejected. Unfortunately, they make no use of the distinction between extreme adaptationism and strong adaptationism to clarify the extent to which their selectionist theory is testable as a theory of language/the language faculty as a whole. That is, they do not consider a question like the 
following: If this theory were taken as strongly adaptationist, about which subset of the most salient features of language/the language faculty should it express claims to be testable as a theory of the evolution of the language faculty as a univocal object? In consequence, the testability of Pinker and Bloom's selectionist theory remains obscure in a nontrivial way.

\subsection{Evolutionary phases}

Theories of language evolution are intended to give an account of a phenomenon that is referred to with the aid of terms such as "evolution", "origin", "emergence", "development", "maintenance" and so on. Even in some relatively sophisticated theories, however, the ontological import of these terms is not explicated sufficiently well in regard to ontological import. In particular, what is often left unclear is the identity of the constituent phases in the overall process of language genesis to which the terms in question are supposed to refer. Let us consider two cases in point.

As for the first, Pinker and Bloom (1990, pp. 707 - 708) offer an account of what they call the "evolution" or "origin" of language/the language faculty. But it is less than clear precisely what phase in the genesis/development of (the) language (faculty) they mean to denote by the terms evolution and origin. Thus, in his commentary on the article, Mark Ridley (1990, p. 756) makes the following "point" about "the nature of modern adaptationism":

"The question of why a character [i.e., a component of the phenotype - R.P.B.] originally evolved is an interesting one, but it may be worth stressing that most modern work on adaptation is not directly concerned with it. Such methods as optimization (Maynard Smith 1978) and game theory (Maynard Smith 1982) consider only how natural selection maintains a character in a population. They are concerned with whether mutant forms of the character will spread. Earlier work on adaptation was also concerned with this question. The adaptationist's question has the scientific merit of accessibility. In some cases, it is easy to test whether natural selection favors a variant of a character.

I realize that the dispute between Pinker and Bloom, and Piattelli-Palmarini, Gould, and Chomsky concerns the origin, not the maintenance, of language by natural selection." (Ridley, 1990, p. 756). 
Pinker and Bloom's response to Ridley's distinction between the origin and the maintenance/spread of a character and to his reading of the dispute in question is quite interesting. To begin with, they give him credit for making

"the interesting point that the origin of a structure and the maintenance of a structure are different questions in evolutionary biology, and that often the tractable scientific work, driven by analyses of selective pressures and adaptive design, is restricted to the latter." (Pinker and Bloom, 1990, p. 765).

Next, Pinker and Bloom draw a distinction, differing at least terminologically from Ridley's, between the origin of a character (or structure) and its maintenance [Emphases added - R.P.B.]:

"We note that for similar reasons, the appearance of a structure in its initial form is a different matter from the elaboration and complication that leads to its fulfilling its current function." (Pinker and Bloom, 1990, p. 765).

Finally, with the aid of the distinction between a structure's appearance in its initial form and the structure's elaboration and complication, they attempt to clarify the nature of the evolutionary phase of (the) language (faculty) on which they mean their selectionist account to focus:

"We believe that this distinction helps explain why [accounts of - R.P.B.] the evolution of language [have] gotten the bad reputation of unmotivated storytelling. In fact, it is reconstructions of the origin of language, from 'bow-wow' theories onward, that are often tainted by a lack of constraining evidence and far-fetched efforts to find precursors. Our strategy is different: We say virtually nothing about the precursors and very first forms of language and the specific sequence leading to its current form (...); we instead focus on evidence of adaptation from signs of design in synchronic language structure and acquisition, where the data are rich and abundant." (Pinker and Bloom, 1990, pp. 765 766).

These remarks give rise to various questions: Is Pinker and Bloom's distinction 'appearance in the initial form versus elaboration and complication' distinct in ontological import from Ridley's distinction 'origin versus maintenance/spread' in the sense that the corresponding terms denote distinct evolutionary phases? For example, do Ridley's term(s) 'maintenance/spread' and Pinker and Bloom's expression 'elaboration and complication' refer to the same evolutionary phase? Which of the phases in question is in fact the focus of Pinker and Bloom's selectionist account and which is at issue in the dispute mentioned by Ridley? The origin, as suggested by Ridley? Or some later phase, as Pinker and Bloom seem to suggest? 
Wilkins and Wakefield's (1995) theory of "the emergence of the neural preconditions for language" is a second instance of a theory of language evolution which is ambiguous about the evolutionary phase for which it aims to offer an account. On the one hand, they (1995, p. 179) state that it falls outside the scope of their BBS target article "to speculate on how language [as a formal grammatical system - R.P.B.] evolved once [this] emergent capacity came into existence". They thus draw a distinction between an evolutionary phase in which the neurolinguistic preconditions for or "neuroanatomical substrate" of language "emerged" and a subsequent phase in which language evolved "toward complexity". On the other hand, Wilkins and Wakefield (1995, p. 205) portray Pinker and Bloom's (1990) selectionist theory as an "alternative approach". This is quite confusing since, on the face of it, Wilkins and Wakefield's theory and Pinker and Bloom's theory are theories about different phases in the evolution of language: whereas the former is a theory of a phase before language appeared in its initial form, the latter is a theory of a phase after language had appeared in its initial form. If Wilkins and Wakefield seriously consider Pinker and Bloom's theory to be an "alternative" to their own, the claims expressed by their own theory are quite obscure in regard to ontological import and, consequently, not testable-in-principle. And this is true of all theories of language evolution which are proposed outside the framework of a principled distinction between the phases that should be distinguished in the evolution of a (biological) entity such as language.

\section{Evidential determinacy}

To be testable, a theory $T$ has to meet various conditions other than that of ontological transparency, including the following conditions of evidential determinacy:

(5) It must be possible -

(a) to state what evidence, if available, would bear in principle on the correctness of the test-implications of $\mathrm{T}$;

(b) to bring some evidence of the sort referred to in (a) to bear in practice on the correctness of specific test-implications of $T^{20}$ 
If $\mathrm{T}$ failed condition (5)(a), it would be evidentially indeterminate in principle, hence untestablein-principle. Were it to fail condition (5)(b), it would be evidentially indeterminate in practice, hence untestable-in-practice.

The evidential indeterminacy of a theory should not be confused with the underdeterminedness by evidence of a theory. By their very nature, all nontrivial empirical theories are underdetermined by the evidence. That is, the evidence for a nontrivial theory cannot furnish conclusive proof of its truth. Such a theory will always express claims which go beyond the evidence which was initially adduced for it. It is accordingly not a serious criticism of a theory to say that it is underdetermined by the evidence. To say, however, that a theory is evidentially indeterminate is to say that it is non-empirical, which is a serious criticism in empirical science. For it is to say one of two things about this theory: (a) that there is no evidence in principle which can be brought to bear on the truth of this theory, or (b) that it is impossible in practice to obtain fragments of the evidence bearing in principle on its truth. So, how well do recent theories of language evolution stand up to scrutiny from the perspective of evidential determinacy?

\subsection{Theories of the evolution of language}

In section 2.2.1 above, it was shown that Pinker and Bloom (1990) seem to be saying in some passages of their BBS target article/response that language and the language faculty are different entities. In some passages, moreover, they refer to the evolution of "language" and in others to the evolution of the "language faculty". If this distinction were to have any substance, questions such as the following could be asked: Is there what is traditionally called a "domain of facts" about language which is not at the same time a domain of facts about the (initial state of the) language faculty? More specifically: Is there a domain of facts about the evolution of language which is not a domain of facts about the evolution of (the initial state of) the language faculty as well? If it were impossible to identify such a separate a domain of facts - and this seems to be the case - theories about the evolution of language would in principle be evidentially 
indeterminate, hence untestable-in-principle. The former question and latter possibility are not considered in the literature, not even in relatively sophisticated discussions such as Pinker and Bloom's (1990). Nevertheless, these questions arise within all linguistic ontologies that distinguish between language and the language faculty or an (underlying) language capacity.

\subsection{Theories of the evolution of the language faculty}

Which brings us to the question of the evidential determinacy of theories of the evolution of the entity called "the language faculty" in generative grammar or entities referred to with less ontological specificity as "a/the language capacity" or "functional language areas" in nongenerative linguistic ontologies. Are there domains of data from which evidence can be derived for testing such theories? In the literature, provision is made for two such domains: one of historical data and one of nonhistorical data.

\subsubsection{The domain of historical data}

Mental faculties do not fossilize (a point routinely made). Consequently, there are no data of a historical sort which could be brought to bear directly on the truth of theories of the evolution of the language faculty. There are some data of a historical sort, though, which are assigned the status of data about "correlates of language". And such data have been taken to bear indirectly on the truth of some of the theories in question, thereby constituting a potential source of indirect historical evidence for or against the theories in question. These data are conventionally assigned to two categories, those of paleontological data and anthropological data, which are sometimes lumped together as "paleoanthropological data". Paleontological data are conventionally taken to include data about fossil remains of hominid skulls and corresponding endocasts; anthropological data conventionally include data about (fragments) of products of hominid cultural behaviour. ${ }^{21}$

The question here is this: How much could evidence derivable from the above-mentioned categories of data about "correlates of language" contribute to the evidential determinacy of 
theories about the evolution of the language faculty? The significance of such evidence is limited in various ways, including the three to be considered directly below.

First, the body of indirect historical data is severely restricted in size, as noted, for example by Wilkins and Wakefield (1995) with reference to paleontological data:

"There is however, an extreme paucity of appropriate material. There are presently only some 40 to 50 endocasts of fossil hominids available for study, and most of these are incomplete (Holloway, 1983a)." (Wilkins and Wakefield, 1995, p. 165).

With reference to what he calls "paleoanthropological data", Byme (1995) has made a similar observation:

"The signs that the paleoanthropological detectives [in pursuit of an account of the evolution of the language faculty or other cognitive capacities - R.P.B.] have to go on are few and problematic to interpret - just stone artefacts, supplemented only for the past million years by signs of dwellings, cave paintings and a wider range of bone and other remains." (Byrne, 1995, p. 165).

The limited size of specifically the fossil record, Byme (1995) moreover observes, is not accidental and does not represent merely "an unlucky and temporary set back", as some scholars optimistically seem to believe:

"Hominids were not marine animals, whose bodies would be more likely to fossilize, the fossil record of ancestors of any particular current terrestrial species is probably just as tiny." (Byme, 1995, p. 5).

The epistemological consequences of the paucity of such indirect historical data are considerable, as Byme (1995) observes:

"We can hope that the next expedition will put it all right, but we will most likely hope in vain. Because of this, the conclusions will always be speculative, fragile and liable to tumble at the sight of new evidence." (Byme, 1995, p. 5).

Second, the import of the available indirect historical data is often unclear, which makes their interpretation problematic. The same data are more often than not susceptible to mutually incompatible interpretations, a point Byme (1995) illustrates as follows:

"Also obvious are the major disagreements between writers about the interpretation of the same evidence. Homo occurred late, Homo occurred early; language is recent, language is ancient; human ancestors went through a seed-eating phase, a scavenging phase, a 
gestural language phase, even an aquatic phase. The same fossil hominids are, in one version, a series of direct human ancestors forming a chain that leads towards ourselves; in other, they become dead-end branches, with the crucial ancestors few and far between, or missing altogether. (Byme, 1995, p. 4).

In Byme's (1995) view, not even sophisticated modern techniques will significantly change this state of affairs. He illustrates this point with reference to the use of computer modelling in fixing the time of the origin of speech:

"Computer modelling of the vocal tract of a Neanderthal suggested that their larynx was a very different shape to that of modem humans: Neanderthals could not have produced the range of vowels that we can. However, the same technique applied to chimpanzees 'shows' that they cannot produce sounds that they do in fact produce. Humans can even produce intelligible speech after removal of the larynx. Claims about Neanderthal speech are bound to be fragile things. The recent find of a hyoid bone (a small bone closely attached to the larynx) indicates a larynx much like ours in a human of 60000 years ago, predating most Neanderthals. This date is also 20000 years before the cave paintings of France and Spain, which are often argued to signal the beginning of symbolic ability in our ancestors - and thus, supposedly, date the origin of language." (Byrne, 1995, p. 5).

Third, the so-called material "correlates of language" and of the language faculty - of which these "correlates" are taken to be indices - and the language faculty belong to quite different ontological domains. Being the kind of entity they are, these "correlates" do not reflect the properties of the language faculty - or, for that matter, of any cognitive language capacity - in a direct way. Reduced to the essence: being the kind of thing they are, fossilized (fragments of) skulls do not contain direct information about cognitive faculties or capacities, being the different kind of thing they are. Consequently, to bring data about "correlates of language" to bear on the truth of claims about the language faculty, this ontological gap has to be bridged in a proper way. Unless this is done, it will be unclear whether the former data are indeed relevant to the truth of the latter claims. In the absence of such clarity, these claims lack the evidential determinacy required by the testability condition.

The question, then, is how the ontological gap between the "correlates of language", on the one hand, and the language faculty or capacity, on the other hand, can be bridged in order to make data about the former relevant to the truth of claims about the (evolution of the) latter. The 
discussion of Wilkins and Wakefield's (1995) BBS target article is instructive in this regard, in that it illustrates the use of two of the basic devices available for bridging the gap between fossil skulls or endocasts on the one hand and the language faculty, a/the language capacity or "functional language areas" on the other hand. The two devices are: inferential jumps and bridge theories.

As for the inferential jumps in question, these include the following:

(6)(a) From data about the volume of fossil skulls, inferences are drawn about the size of the ancestral brains (that were once) contained in them; alternatively, these inferences are drawn from data about endocasts of these brains.

(b) From data about impressions on the interior surface of fossil skulls - or corresponding bumps or ridges on the exterior surface of endocasts - inferences are drawn about the sulcal pattern of the ancestral brains (that were once) contained in them.

(c) From the inferences drawn about ancestral brain seize as in (6)(a), further inferences are drawn about the ancestral brains' (neural) information-processing capacity.

(d) From the inferences about ancestral brains' sulcal pattern, arrived at as in (6)(b), further inferences are drawn about the ancestral brains' anatomical organization.

(e) From the inferences about the ancestral brains' anatomical organization, arrived at as in (6)(d), further inferences are drawn about the ancestral brains' general functional organization.

(f) From the above-mentioned (further) inferences about the (size of the) ancestral brains' processing capacity, their anatomical organization and their functional organization, (still) further inferences are drawn about - amongst other things - the presence, in the ancestors, of the cognitive entity/entities called "the language faculty", "a/the language capacity" or "functional language areas".22

By executing (some of) the inferential jumps listed in (6) one after the other, the gap between properties of fossil skulls or endocasts on the one hand and the presence of the language faculty, 
a/the language capacity or "functional language areas" on the other hand can be bridged in the following way:

(7) I II

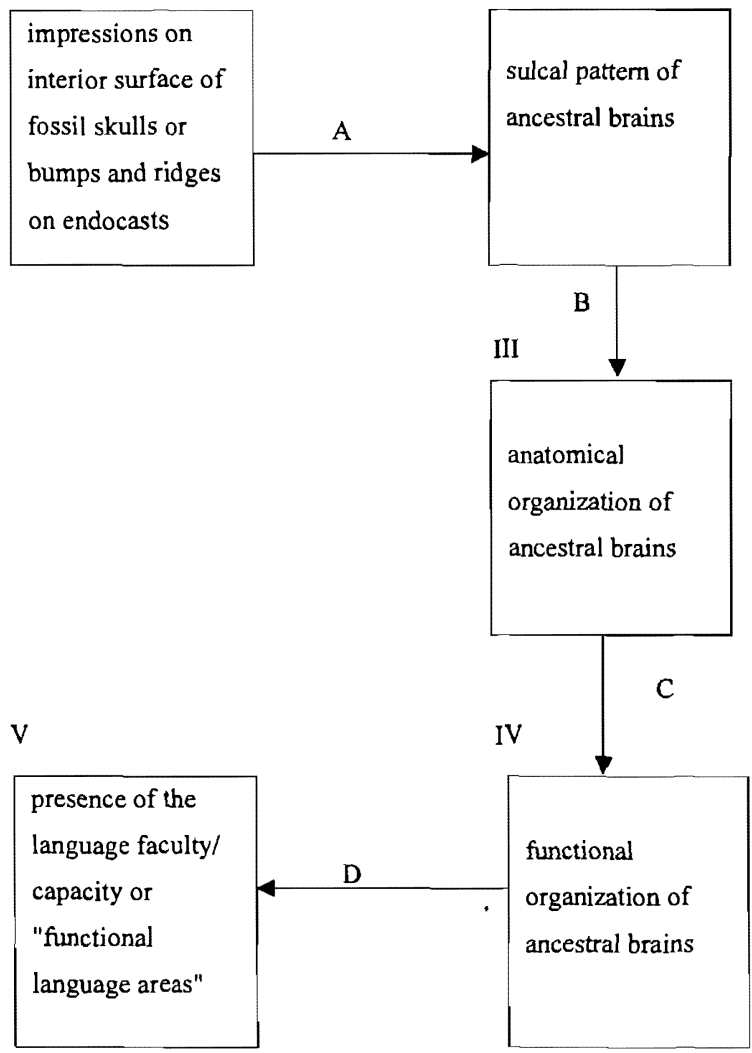

The portrayals in (6) and (7) of the inferences in question are simplified throughout in an important sense: they do not reflect the consequences of the distinction that has to be drawn 
between the presence or absence of the language faculty etc., which is a state, and its evolution or evolutionary emergence, which is an event or process. As represented in (6) and (7), the inferences are inferences to conclusions about the state. To be able to draw conclusions about the event or process, however, one requires a number of further inferential jumps. These, in essence, involve the following: From (a) inferred changes in the ancestral brains' size and sulcal pattern and (b) inferred changes in the ancestral brains' processing capacity, anatomical organization and/or functional organization, further inferences are drawn about the event or process referred to as "the evolution/evolutionary emergence of language". These changes cannot simply be "read off" indirect historical data about the entities in question; they too, therefore, have to be inferred. This means that the total set of inferential jumps needed to bridge the ontological gap between data about properties of fossil skulls or endocasts and properties of the process by which the language faculty etc. evolved is considerably more complex than it is depicted in (6) and (7).

Which brings us to what is problematic about inferential jumps such as those indicated by A - D in (7). First, there is the question of their validity. Why should they be considered valid at all? That is, what are the warrants that "license" these inferential jumps? This is where the second device mentioned above comes into play. The inferential jumps in question derive whatever validity they have from (sets of) assumptions about the way in which properties of entities of one ontological domain are systematically interrelated with properties of entities of another ontological domain. The different domains of entities are represented by the numbered boxes in (7). A suitably structured set of assumptions which systematically interlink properties of entities of one ontological domain with properties of entities of another ontological domain functions as a bridge theory. ${ }^{23}$ Underlying - and warranting or "licensing" - each of the inferential jumps indicated by $\mathrm{A}-\mathrm{D}$ in (7), there has to be a distinct bridge theory. For example, the inferential jump A from properties of fossil skulls or endocasts to those of sulcal patterns is "licensed" by what Wilkins and Wakefield (1995) call a theory of "the mechanics of deformation". This theory assumes in general terms that:

"The deformational behavior or any solid, including the brain ... is determined by its mechanical attributes, which, in tum, are determined in large part by the micro-structural 
properties of the material (strength of atomic bonds, packing order of molecules, larger constituents, etc.)." (Wilkins and Wakefield, 1995, pp. $165-166){ }^{24}$

To determine the validity of the various inferential jumps provided for in (6), the merits of the underlying bridge theories have accordingly to be appraised. From such appraisal, three general points emerge.

First, the individual constituent assumptions of the various bridge theories are on the whole neither stated nor justified explicitly. Wilkins and Wakefield's explicit statement and discussion of the theory of "the mechanics of deformation" is exceptional in this context.

Second, the various "licensing" assumptions are not "parcelled out" explicitly into different bridge theories but are regularly lumped together into a single internally unstructured collection, inaccurately referred to by some as "a neuropsychological theory/model". By implication, this holdall theory has the job of "licensing" a single inferential leap directly from (properties of) fossil skulls or corresponding endocasts to the presence (and properties of) the language faculty, a/the language capacity or "functional language areas". This single inferential leap - which, in fact, is a bundle of conflated inferences - has been seriously questioned by, amongst others, Merlin Donald (1995), who observes in his commentary on Wilkins and Wakefield's (1995) target article that:

"whether surface anatomy could directly support an inference of a specific cognitive capacity in a given brain would depend entirely on which neuropsychological model of higher cognition was adopted." (Donald, 1995, p. 188).

Third, some bridge theories - or their constituent assumptions - are quite controversial. Here for example, are the terms in which Wilkins and Wakefield (1995) qualify their own adherence to the bridge theory that is assumed to "license" the inference of (anatomical) brain organization from sulcal pattern - indicated by $B$ in (7):

"The claim that [brain - R.P.B.] organization can be inferred from sulcal pattern is admittedly controversial." (Wilkins and Wakefield, 1995, p. 165). 
We will return to the consequences of this "admission" by Wilkins and Wakefield below. Notice, first, that the theory that cognitive functions in general and linguistic functions in particular are localized in the brain in some simple way is equally controversial, as is observed by Donald (1995) amongst others:

"W\&W apparently feel they can safely conclude that it was specifically language capacity that came into existence in habilines, because they subscribe to a variant of the Wernicke/Geschwind theory that postulates two cortical language areas of relatively fixed localization, supporting two relatively discrete linguistic subsystems. Given that model, the presence of a negative impression of the language brain on the interior cranial surface of habilines would suggest that language capacity (as opposed to something else) was present in their brains. However, many neuropsychologists would no longer agree that the left anterior and posterior tertiary zones necessarily constitute, in any simple or straightforward way, the neurological location of language skill. The linguistic functions of these specific brain regions do not seem as fixed or localized as they did even 10 years ago. The cortical tertiary zones under debate seem to be involved in a variety of higher functions, of which language is undoubtedly one, but the case for the classical notion of two distinctive, easily localizable cortical regions specifically devoted to language is not strong." (Donald, 1995, p. 188).

As regards the way in which the brain's anatomical organization and functional organization are interrelated, Harry Jerison (1995) is another BBS commentator who cautions against assuming a close symmetry:

"I agree that there is no good evidence from paleoneurology for functional asymmetry in the brain ...., but W\&W [i.e., Wilkins and Wakefield - R.P.B.] should be almost as skeptical about the evidence from comparative neurology, which is weaker than the present consensus suggests. The anatomical basis of functional asymmetry in living brains remains poorly understood." (Jerison, 1995, p. 195).

Some of the grounds for questioning the closeness of the links which certain neuropsychological theories assume between anatomical and functional organization have been (re)stated by Elizabeth Whitcombe (1995) in her commentary on Wilkins and Wakefield's target article:

"The functional anatomy of the human brain is not yet known in detail (Crick \& Jones 1993). The conventional maps of cerebral or cortical function have been compiled from disparate sources; extrapolations from animal experiments are juxtaposed with topographical pathology associated with disorders of higher cerebral function. Demarcations are constantly under revision, whereas the relations between cortical and subcortical areas and pathways, and between the sensorimotor and the psychosensorimotor remain obscure. The use of endocasts as evidence of anatomical, let 
alone functional, organization is compromised (despite increasing sophistication in reconstruction) by physical limitations: detailed configurations of even major sulci and gyri of the normal adult brain leave no impressions on the inner surface of the skull from which the endocast is taken." (Whitcombe, 1995, p. 204).

Similarly skeptical views are expressed independently by Philip Lieberman (1995) in his commentary on Wilkins and Wakefield's target article:

"The neurological insights that can be gained from the study of endocasts are probably even less determinate than the stone tool record. The neocortical areas essential for speech and language differ from the traditional textbook sites of Broca's and Wernicke's areas and vary from person to person (Kimura 1993; Ojemann et al. 1989). Furthermore, both brain stimulation (Ojemann \& Mateer 1979) and lesion studies (Kimura 1993) show that the neocortical areas involved in manual and speech motor control differ, though they are close to each other. These functional distinctions are not evident when neurosurgeons look at living human brains. It would probably be impossible to determine whether $H$. habilis was capable of speech and syntax even if we examined a perfectly preserved $H$. habilis brain. In short, inferences concerning the function of neocortical areas based on endocasts are exceedingly speculative." (Lieberman, 1995, p. 198).

The question, of course, is: How much weight should we accord to critical comments and questions such as those framed by Donald, Jerison, Lieberman, Whitcombe and others about the validity of inferences from data about fossil skulls to functional linguistic capacities or functional linguistic properties of brains? In this connection, it is interesting to consider the position which Wilkins and Wakefield (1995) fall back to in defending such inferences:

"We leave the validation of the field [of paleoneurology - R.P.B.] as a whole to those who are most familiar with the data. We allow, however, that if the credibility of the paleoneurological enterprise is ultimately found to be incompatible with guidelines for scientific endeavours in a more general sense, then our account loses some of its tenacity." (Wilkins and Wakefield, 1995, p. 218).

These remarks hardly amount to a strong defence of the bridge theory/theories in question and, by implication, of the inferential jump/jumps which of necessity derive their validity from these theories.

In sum: there is a significant ontological gap between, on the one hand, (properties of) fossil skulls or corresponding endocasts and, on the other hand, (properties of) a cognitive capacity 
such as the language faculty, a/the language capacity or "functional language areas". Inferences from the former properties to the latter can be drawn indirectly only and, moreover, depend for their validity on various bridge theories. Since central assumptions of these theories often are (a) unexplicated, (b) not interlinked in any clear way, and/or (c) controversial in what they assert, it is not evident that data about properties of fossil skulls or corresponding endocasts are properly relevant to the truth of claims about (the presence and evolution) of the language faculty, a/the language capacity or "functional language areas". Which implies that it is not evident that the former data can confer on theories of language evolution the required measure of evidential determinacy. ${ }^{25}$

\subsubsection{The domain of nonhistorical data}

Some scholars working in evolutionary linguistics are well aware of the limitations of historical data of the sort considered above. And some have even proposed approaches to the study of language in which reliance on such data is claimed to be fully or partly eliminated. Thus, in attempting to counter the skepticism about whether "anything of scientific value" could be said about language evolution, Pinker and Bloom (1990) draw attention to the availability of nonhistorical data about grammatical structure:

"A major problem among even the more responsible attempts to speculate about the origins of language has been that they ignore the wealth of specific knowledge about the structure of grammar discovered during the part 30 years." (Pinker and Bloom, 1990, p. 727).

And they go on to identify various other sources of new, nonhistorical, "information" about language evolution:

"We think there is a wealth of respectable new scientific information relevant to the evolution of language that has never been properly synthesized. The computational theory of mind, generative grammar, articulatory and acoustic phonetics, developmental psycholinguistics, and the study of dynamics of diachronic change could profitably be combined with recent molecular, archaelogical and comparative neuroanatomical discoveries and with strategic modeling of evolution using insights from evolutionary theory and anthropology ...." (Pinker and Bloom, 1990, p. 727). 
Pinker and Bloom's position, in essence, is that there are sufficient data of a nonhistorical sort on the basis of which something of "scientific value" can be said about language evolution. In view of the significance attached by them to a condition of testability, this would seem to imply that theories about language evolution need not depend for their evidential determinacy on evidence other than that derived from nonhistorical data. If this were indeed the case, Pinker and Bloom would have succeeded in overcoming a major obstacle to doing work of "scientific value" in evolutionary linguistics. Which gives rise to the question: How do Pinker and Bloom go about utilizing nonhistorical data at a level of specifics?

The strategy adopted by Pinker and Bloom (1999, p. 721) for achieving this includes the following components amongst others: ${ }^{26}$

(8)(a) Operating within a selectionist perspective, the make - in the form of what they call "postulates" - a number of claims about the actual process by which language (in the sense of "the initial state of the language faculty") evolved.

(b) They assert that "what we do know from the biology of language and evolution makes each of the postulates quite plausible" and proceed to defend the above-mentioned "postulates" with the aid of data about the biology of language.

As for (8)(a) : Pinker and Bloom's postulates include the following:

(9)(a) "There must have been genetic variation among individuals in their grammatical competence." (Pinker and Bloom, 1990, p. 721).

(b) "There must have been a series of steps leading from no language at all to language as we find it ...." (Pinker and Bloom, 1990, p. 721).

(c) "... each step [must have been] small enough to have been produced by a random mutation or recombination ... ." (Pinker and Bloom, 1990, p. 721).

(d) "... each step [must have been] useful to its possessor" (Pinker and Bloom, 1990, p. 721). 
(e) "Every detail of grammatical competence that we wish to ascribe to selection must have conferred a reproductive advantage on its speakers." (Pinker and Bloom, 1990, p. 721).

(f) "... this advantage must be large enough to have become fixed in the ancestral population." (Pinker and Bloom, 1990, p. 721).

(g) "... there must be enough evolutionary time and genomic space separating our species from nonlinguistic primate ancestors." (Pinker and Bloom, 1990, p. 721).

Formulated in a "must be/must have been" modality, these postulates do not express simple historical claims which collectively offer a reconstruction of the actual process by which language evolved. Yet, by observing that "various people" have claimed each of $(9)(\mathrm{a})$ - (g) to be "'false" and by defending them against such criticisms, Pinker and Bloom (1990, p. 721) indicate that they consider these postulates falsifiable or testable; they concede, though, that "[t]here are no conclusive data on any of these issues". The question, of course, is:. Do the biological data offered by Pinker and Bloom in defence of an individual postulate $\mathrm{P}$ bear on $\mathrm{P}$ in such a way as to make $P$ evidentially determinate? Let us consider this question with reference to Pinker and Bloom's argument that postulate (9)(a) is not false but rather "quite plausible".

In defending postulate (9)(a) against criticisms by Lieberman (e.g., 1984), Pinker and Bloom make the following claims:

(10)(a) There does exist variation in grammatical ability. (Pinker and Bloom, 1990, p. 721).

(b) At least some of this variation is (suspected to be) genetic. (Pinker and Bloom, 1990, p. 721).

In support of (10)(a), Pinker and Bloom assert that:

(11) "We all know some individuals who habitually use tangled syntax and others who speak with elegance, some who are fastidious conformists and others who bend and stretch the language in various ways." (Pinker and Bloom, 1990, p. 721). 
In support of $(10)(b)$, Pinker and Bloom refer to:

(12)(a) "experimental data [collected by Bever et al. (1989) - R.P.B.] showing that righthanders with a family history of left-handedness show less reliance on lexical association than people without such a genetic background." (Pinker and Bloom, 1990, pp. 721 - 722);

(b) data about "documented genetically transmitted syndromes of grammatical deficits". (Pinker and Bloom, 1990, p. 722).

In their attempt to show that postulate $(9)(a)$ is "quite plausible", Pinker and Bloom use the argument which can be reconstructed schematically as follows, with the arrows representing (putative) relations of support:

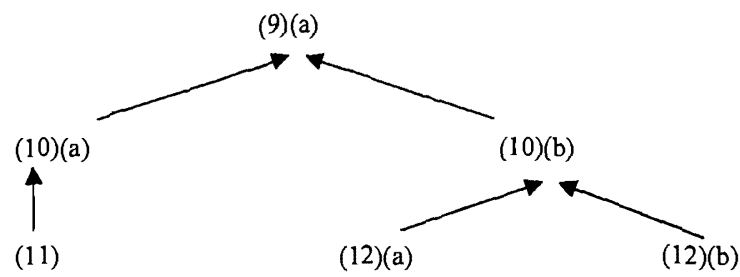

Of the various factors that contribute to the nonconclusive nature of this argument, one is particularly pertinent here: the supporting claims and the supported claims are not claims about the same entities or phenomena. Thus, postulate (9)(a), the main claim in need of support, expresses an assertion about a property (genetic variation) of entities (individuals' respective grammatical competences) that existed at a certain time, a time in the past. (Let us refer to these entities as ' $\mathrm{GC}_{\text {pasi.) }}$ Supporting claims (10)(a) and (b), however, express assertions about a property (genetic variation) of entities (namely, individuals' respective grammatical abilities) that exist at a different time, a time in the present separated from the former time in the past by tens

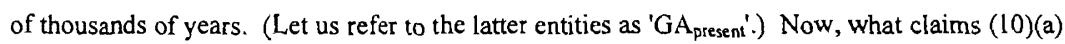


and (b) assert about $\mathrm{GA}_{\text {present }}$ is relevant to what postulate (9)(a) asserts about $\mathrm{GC}_{\text {past }}$ only if certain bridge assumptions are made about differences/similarities between $\mathrm{GC}_{\text {past }}$ and $\mathrm{GA}_{\text {present }}$. Central among these bridge assumptions are the following:

(14)(a) There are many differences between $\mathrm{GA}_{\text {present }}$ and $\mathrm{GC}_{\text {past, }}$ differences caused by processes through which $\mathrm{GA}_{\text {present }}$ evolved out of $\mathrm{GC}_{\text {past; }}$; nevertheless $\mathrm{GA}_{\text {present }}$ is still identical to $G C_{\text {past }}$ in regard to a number of fundamental properties.

(b) Genetic variation is a property in regard to which $\mathrm{GA}_{\text {present }}$ is identical to $\mathrm{GC}_{\text {past }}$ and which, consequently, $\mathrm{GA}_{\text {present }}$ did not acquire in the process by which it evolved out of $\mathrm{GC}_{\text {past. }}$.

Without these and other bridge assumptions, not one of which is necessarily true, (10)(a) and (b) do not bear on the correctness of postulate (9)(a) at all. I have assumed above that Pinker and Bloom use the expressions "grammatical competence" and "grammatical ability" as synonyms: if this assumption is false, they will have to make additional bridge assumptions warranting an inference from the properties of one entity, namely grammatical competence, to the properties of another, distinct entity, namely grammatical ability.

As for (10)(a), to be able to offer (11) in support of (10)(a), certain bridge assumptions have to be made as well since the respective claims of (10)(a) and (11) do not express assertions about the same entity. (10)(a) expresses a claim about grammatical ability, which (presumably) is the entity also referred to by means of the expressions "grammatical competence" or "tacit knowledge of (the grammar) of language". Clearly (11), however, refers to an entity other than "grammatical ability". This distinct entity may be either that known as "linguistic performance" or that known as "the ability to use language"; Pinker and Bloom do not make it clear which of these two entities they intend to refer to. Within a well-articulated linguistic ontology, such as that developed by Noam Chomsky, linguistic ability in the sense of "linguistic competence", linguistic performance and the ability to use language are three distinct entities. ${ }^{27}$ And to be able to bring data about (say) the ability to use language to bear legitimately on the correctness of a 
claim about variation in "grammatical competence", it is necessary to make bridge assumptions that warrant this inferential jump.

Which brings us to what is involved when the data alluded to in (12)(a) are offered in support of the claim about genetic variation expressed in (I0)(a). These data concem the way in which a certain category of people - right-handers with a family history of left-handedness - actually process utterances. The claim, by contrast, asserts something about the nature of the variation in a certain state of an abstract mental faculty. The data are not data about this entity and, as such, are not relevant to the truth of claims about it unless suitable further assumptions are made. At an appropriate level of specificity, these further assumptions have to characterize the way in which a certain kind of processing - the kind engaged in by right-handers with a family history of left-handedness - is systematically interrelated with variation in grammatical ability. Understandably, these further assumptions (= bridge assumptions) must themselves be empirical and, moreover, supported by actual evidence. The gap between the relevant properties of the processing under consideration and those of the grammatical variation at issue, obviously, cannot be bridged in a purely speculative or arbitrary way. The same applies to bridging the gap between the properties of this variation and the properties of the grammatical deficits referred to in (12)(b).

In their defence of postulate (9)(a), Pinker and Bloom do not dwell on the make-up of their argument reconstructed in (13) above. And, even more pertinent, they do not spell out the various bridge assumptions which have to be made in order to bring the data referred to in (11), (12)(a) and (12)(b) to bear, via claims (10)(a) and (10)(b), on the correctness of postulate (9)(a). It is accordingly not clear that the nonhistorical data in question contribute to the evidential determinacy - and, ultimately, the testability-in-principle - of the historical claim expressed by postulate (9)(a). Pinker and Bloom seem to judge sufficient the blanket qualification that "[t]here are not conclusive data on any of these issues". To show that postulate (9)(a) is testable, they have to do more however: they have to make clear whether they would have considered this postulate faisified if, for example, data about the processing performed by right-handers with a 
family history of left-handedness were such that these data contradicted test-implications of postulate (9)(a). Or, whether they would be willing to consider postulate (9)(a) falsified if there were data about grammatical deficits that clashed with some of (9)(a)'s test-implications. More generally, if Pinker and Bloom were not willing to assign these processing and deficit data the status of potentially falsifying evidence, it is not clear how they could maintain that postulate (9)(a) expresses a testable claim. The same applies to their view of the data which they cite in defence of their other process postulates.

So, how does the above discussion bear on the evidential determinacy - and testability - of theories of language evolution? In section 4.2.1, it was shown that historical evidence (of a paleontological sort) cannot confer the necessary (measure of) evidential determinacy on theories about language evolution: the inferences drawn from such data about the presence and the evolution of the language faculty, a/the language capacity or "functional language areas" are quite indirect and not sufficiently "well-licensed" by the required bridge theories. In the present section (4.2.2), it was shown that nonhistorical data of the kind cited by Pinker and Bloom are subject to essentially the same limitation. Such (biological) data can be brought to bear on claims about language evolution at best indirectly, and then only if a number of bridge assumptions were adopted to "license" or warrant the inferential jumps involved. And these bridge assumptions have not been explicated fully or justified systematically.

\section{Conclusion}

What, then, has the analysis offered in the preceding sections revealed about the testability - and, by implication, the scientific respectability - of some of the more sophisticated theories of language evolution? In essence, that these theories exhibit two properties which substantially diminish the extent to which they are testable-in-principle:

15(a) They express claims which are ontologically opaque.

(b) They express claims which are evidentially indeterminate. 
The ontological opacity of the theories is caused by, amongst other things, the lack of a wellarticulated linguistic ontology, the lack of a non-arbitrary distinction among various phases of the overall process of language evolution, and the lack of clarity about the size of the unit(s) "language" or the language faculty as a whole as opposed to specific characteristics of it - whose evolution is at issue. It does not, however, seem to be impossible in principle to eliminate these causes of this ontological opacity.

The evidential indeterminacy of these theories is caused by the existence of an ontological gap between, on the one hand, the entity - "language" or the language faculty - whose evolution is at issue and, on the other hand, certain "indexical" entities from whose properties inferences are drawn about the evolution of the former entities. The various bridge theories which are needed to "license" the inferential jumps across this gap are on the whole poorly developed. But there appears to be no reason which in principle precludes the development of adequate bridge theories. That is to say, it is not impossible in principle to overcome the problem of evidential indeterminacy as a factor which diminishes the testability-in-principle of the theories of language evolution in question.

So, how respectable, then, is the work that has been done in evolutionary linguistics? Work that contributes to overcoming the twin limitations of ontological opacity and evidential indeterminacy is clearly of a respectable sort. Work that exacerbates these limitations instantiates the genre characterized by William Whitney as "mere windy talk".

\section{Acknowledgements}

I would like to thank Walter Winckler for his expert editing of this article. 


\section{NOTES}

*Tel.: +27-21-808-2010; fax: +27-21-808-2009; e-mail: rpb@maties.sun.ac.za

1. It is possible to distinguish various phases in the process by which an entity (or a trait or "character") evolved, a point that will be taken up in section 3.3 below. Here the term "developed" is used in a non-technical way to refer to all evolutionary phases that come after the first phase, that of initial emergence. The term "language" is also used here in a non-technical way here; the limitations of this usage will be discussed in some detail in section 3.1 below.

2. The nature and consequences of this evidential paucity will be discussed in some detail in section 4 below.

3. For this quotation, see Kendon (1991, p. 199) and Stam (1976, p. 256).

4. For this translation, see Kendon (1991, p. 199) and Stam (1976, p. 255).

5. Pinker and Bloom's (1990, p. 726) adaptationist (or selectionist) theory - which will figure prominently in the discussion below - claims in essence that human language, like other biological systems, evolved by natural selection. They base this theory on two facts: "Language shows signs of complex design for the communication of propositional structures, and the only explanation for the origin of organs with complex design is the process of natural selection." (Pinker and Bloom, 1990, p. 726).

6. This analysis builds on the discussion in Botha (1997a, 1997b, 1998a, 1998b, 1999).

7. In this article, the expression "evolutionary linguistics" is accordingly not used to demarcate in a programmatic way a (new) subfield of linguistics. The expression "evolutionary psychology", by contrast, is used in such a way by, for example, Symons (1992, p. 135) and by Cosmides, Tooby and Barkow (1992, pp. 3, 7) for demarcating a 
(new) subfield of psychology, one concerned with the "application of the adaptationist programme to the study of the human mind/brain" (Symons, 1992, p. 135).

8. Pinker and Bloom (1990) and Wilkins and Wakefield (1995) are target articles in Behavioral and Brain Sciences (= BBS), followed by commentaries by a considerable number of 'peers', followed by the 'target' authors' responses. Hurford, Studdert-Kennedy and Knight (eds.) (1998) is a collection of papers presented and discussed at the 1996 Edinburgh conference on approaches to the evolution of human language.

9. In the relevant literature on the evolution of language, the terms "testable", "refutable" and "falsifiable" are loosely used as synonyms.

10. In his commentary on Wilkins and Wakefield's (1995) BBS target article, Phillip Tobias (1996, p. 792) observes that: "These three prevailing concepts - which may be summed up as motor redeployment, sensory redeployment, and linguist [sic] function $a b$ initio address the question posed at the outset: On what substrate did natural selection go to work to produce the speech centers in the cerebral cortex? Testability is considered the hallmark of a good, rigorous hypothesis. Converting these three notions into testable hypotheses (and testing them!) will measure the ingenuity of palaeoneurobiologists well into the twenty-first century".

As is clear from Schepartz (I993, p. 120), a condition of testability is also adopted by anthropologists working on language evolution.

11. These scholars seem to believe, moreover, that the considerations bearing on the testability of theories (as collections of hypotheses) are identical to those bearing on the testability of individual hyporheses.

12. For this distinction, see Botha (1998a, pp. $19-20)$ and the literature cited there. 
13. Consider in this regard also [all emphases added - R.P.B.]: "Many people have argued that the evolution of the human language faculty cannot be explained by Darwinian natural selection". (Pinker and Bloom, 1990, p. 707). And: "... accounting for the evolution of a language faculty permitting restricted variation is only important on the most pessimistic of views." (Pinker and Bloom, 1990, pp. 715 - 716).

14. Consider in this regard also [all emphases added - R.P.B.]: "A more serious challenge to the claim that grammars show evidence of good design may come from the diversity of human languages". (Pinker and Bloom, 1990, p. 715). And: "The nature of language makes arbitrariness of grammar itself part of the adaptive solution of communication in principle." (Pinker and Bloom, 1990, p. 178).

15. Chomsky (1981, pp. 34 - 35) depicts the language faculty as a "mental organ" or "module of mind" which has two states that are of special significance. The first of these states of the language faculty is the initial state, taken by Chomsky to be "genetically determined" (Chomsky, 1980, pp. 65, 187, 1987a, pp. 34 - 35, 1986, pp. 25 - 26). That is to say, Chomsky sees the initial state of this faculty as incorporating the genetic language programme, or "(the set of) genetically encoded linguistic principles"; this, in turn, he sees as representing the child's innate linguistic endowment. The language faculty is in its initial state in a child that has not had any linguistic experience in the sense of having been exposed to utterances of or data about his/her language. The second significant state of the language faculty is an attained, and stable, state (Chomsky, 1986, pp. 24 - 26). This state develops or grows out of the initial state under the "triggering" and "shaping" influence of the child's linguistic experience (Chomsky, 1980, pp. 33, 34, 45 - 142).

16. For a more detailed discussion of this point, see Botha (1997a, pp. 254 - 256).

17. Conceptually, this flaw could be remedied by abandoning the distinction between "language" and "the language faculty" as wholly terminological. And by taking the 
claims expressed by Pinker and Bloom's theory about the evolution of "language" as claims about the evolution of the initial state of the language faculty.

18. To make his point more concrete, Sober (1990, p. 764) refers to the "human birth canal", observing that it would be a waste of time to wonder whether this was the product of natural selection. Whereas some of the features of this canal may be adaptive, others may not be.

19. Functionless "parts" of the language faculty pose a potential threat to their selectionist theory. For some discussion of this point, see Botha (1997b, pp. 324 - 329).

20. For the way in which the distinction between testability-in-principle and testability-inpractice has conventionally been drawn, see Hempel (1966, p. 30ff.).

21. A distinction is generally drawn between two kinds of endocasts: (a) artificial endocasts, which are latex models of the brains (that were once) contained in fossil skulls, and (b) natural endocasts, which are models of these brains formed by geological processes acting on the skulls in question. For a classification of more common types of "paleoanthrophological" data, see Schepartz (1993, p. 96ff).

22. Non-linguists tend to use the expression "functional language area(s)" for denoting a/the cognitive language capacity.

23. For the role of bridge theories (or, less formally, bridge assumptions) in the logic of linguistic inquiry, see Botha (1980, p. $77 \mathrm{ff}$ ) and Lightfoot (1979, p. 18). Botha (1998a, pp. 36 - 38) shows that such theories or assumptions are necessary to Pinker and Bloom's (1990) selectionist account of language evolution, a point taken up further in section 4.2.2 below as well. 
24. For specifics of this theory, see Wilkins and Wakefield (1995, p. 166).

25. These conclusions about the status of paleoneurological data in the testing of theories of language evolution apply mutatis mutandis to the status of data about stone tool technology in such testing, as is clear from discussions such as Kingdon (1993), Lieberman (1995, pp. 197 - 198) and Deacon (1997, pp. 345 - 349, 365 - 369). The essence of the matter, as phrased by Deacon $(1997$, p. 367), is that "artifacts are not reliable indicators of mental abilities, and that lack of artifacts does not indicate a lack of the potential to produce them". Or, as Lieberman (1995, p. 197) more plainly puts it: "... it is not clear that early stone tools can tell us much about their makers' brains".

26. For a survey of all the components of the strategy adopted by Pinker and Bloom, see Botha (1998b, pp. 242 - 246).

27. For this tripartite distinction, see Botha (1989, Section 2.5.1 and 2.6.1).

\section{REFERENCES}

Aitchison, J., 1998. On discontinuing the continuity-discontinuity debate. In: Hurford, StuddertKennedy, Knight, (eds.), 1998, pp. 17 - 28.

Barkow, J.H., Cosmides, L., Tooby, J., (eds.), 1992. The Adapted Mind. Evolutionary Psychology and the Generation of Culture. Oxford University Press, New York and Oxford.

Berwick, R.C., 1998. Language evolution and the Minimalist Program: The origins of syntax. In: Hurford, Studdert-Kennedy, Knight, (eds.), 1998, pp. 299 - 340.

Bever, T.G., Carrithers, C., Cowart, W., Townsend, D.J., 1989. Language processing and familial handedness. In: Galaburda, (ed.), 1989, pp. 331 - 357.

Botha, R.P., 1980. Methodological bases of a progressive mentalism. Synthese 44, pp. $1-112$. 
Botha, R.P., 1989. Challenging Chomsky. The Generative Garden Game. Basil Blackwell, Oxford.

Botha, R.P., 1997a. Neo-Darwinian accounts of the evolution of language: I. Questions about their explanatory focus. Language and Communication 17, 249 - 267.

Botha, R.P., 1997b. Neo-Darwinian accounts of the evolution of language: 2. Questions about complex design. Language and Communication 17, 319 - 340.

Botha, R.P., 1998a. Neo-Darwinian accounts of the evolution of language: 3. Questions about their evidential bases, logic and rhetoric. Language and Communication 18, $17-46$.

Botha, R.P., 1998b. Neo-Darwinian accounts of the evolution of language: 4. Questions about their comparative merit. Language and Communication 18, 227 - 249.

Botha, R.P., 1999. Discussing the evolution of the assorted beasts called language. Language and Communication 19.

Byrne, R., 1995. The Thinking Ape. Evolutionary Origins of Intelligence. Oxford University Press, Oxford.

Chomsky, N., 1980. Rules and Representations. Columbia University Press, New York.

Chomsky, N., 1981. Principles and parameters in syntactic theory. In: Hornstein, Lightfoot, (eds.), 1981, pp. 32 - 75.

Chomsky, N., 1986. Knowledge of Language: Its Nature, Origin and Use. Praeger, New York.

Cosmides, L., Tooby, J., Barkow, J.H., 1992. Introduction: evolutionary psychology and conceptual integration. In: Barkow, Cosmides, Tooby, (eds.), 1992, pp. 3 - 15.

Crick, F., Jones, E., 1993. Backwardness of human neuroanatomy. Nature 361, pp. $109-110$.

Deacon, T., 1997. The Symbolic Species. The Co-evolution of Language and the Human Brain. Penguin, London.

Donald, M., 1995. Neurolinguistic models and fossil reconstructions. Behavioral and Brain Sciences 18 , pp. $188-189$. 
Donald, M., 1998. Mimesis and the executive suite: missing links in language evolution. In: Hurford, Studdert-Kennedy, Knight, (eds.), 1998, pp. 44 - 67.

Dunbar, R., 1998. Theory of mind and the evolution of language. In: Hurford, StuddertKennedy, Knight, (eds.), 1998, pp. $92-110$.

Galaburda, A., (ed.), 1989. From reading to neurons. MIT Press, Cambridge, MA.

Hempel, C.G., 1966. Philosophy of Natural Science. Prentice-Hall, Englewood Cliffs, N.J.

Hornstein, L.N., Lightfoot, D., (eds.), 1981. Explanation in Linguistics. The Logical Problem of Language Acquisition. Longman, London and New York.

Hurford, J.R., Studdert-Kennedy, M., Knight, C., (eds.), 1998. Approaches to the Evolution of Language. Cambridge University Press, Cambridge.

Jerison, H., 1995. Issues in neo- and paleoneurology of language. Behavioral and Brain Sciences 18, pp. $195-196$.

Kendon, A., 1991. Some considerations for a theory of language origins. Man (N.S.) 26, 199 221.

Kimura, D., 1993. The Neutral Theory of Molecular Evolution. Cambridge University Press, Cambridge.

Kingdon, J., 1993. Self-made Man. Wiley, New York.

Lewontin, R., 1990. How much did the brain have to change for speech? Behavioral and Brain Sciences $13,740-741$.

Lieberman, P., 1984. The Biology and Evolution of language. Harvard University Press, Cambridge.

Lieberman, P., 1995. Manual versus speech motor control and the evolution of language. Behavioral and Brain Sciences 18, pp. 197 - 198.

Lightfoot, D., 1979. Principles of Diachronix Syntax. Cambridge University Press, Cambridge. 
MacNeilage, P., 1998. The frame/content theory of evolution of speech production. Behavioral and Brain Sciences 21, pp. 499 - 511, 532 - 546.

Maynard Smith, J., 1982. Evolution and the Theory of Games. Cambridge University Press, Cambridge.

Maynard Smith, J., 1989. Optimization theory in evolution. In: Sober, (ed.), 1989. [First published in Annual Review of Ecology and Systematics 9, 1987, pp. 31 - 56.]

Ninio, A., 1990. The genome might as well store the entire language in the environment. Behavioral and Brain Sciences 13, pp. 746 - 747.

Ojemann, G.A., Mateer, C., 1979. Human language cortex: localization of memory, syntax and sequential motor-phoneme identification systems. Science 205, pp. 1401 - 1403.

Ojemann, G.A., Ojemann, F., Lettich, E., Berger, M., 1989. Cortical language localization in left dominant hemisphere : An electrical stimulation mapping investigation in 117 patients. Joumal of Neurosurgery 71, pp. $316-326$.

Pesetsky, D., Block, N., 1990. Complexity and adaptation. Behavioral and Brain Sciences 13, pp. $750-752$.

Piattelli-Palmarini, M., 1990. An ideological battle over modals and quantifiers. Behavioral and Brain Sciences 13, 752 - 754.

Pinker, S., Bloom, P., 1990. Natural language and natural selection. Behavioral and Brain Sciences $13,707-727,765-784$.

Power, C., 1998. Old wives' tales: the gossip hypothesis and the reliability of cheap signals. In: Hurford, Studdert-Kennedy, Knight, (eds.), 1998. pp. 111 - 129.

Ridley, M., 1990. Arbitrariness is no argument against adaptation. Behavioral and Brain Sciences 13, p. 756.

Schepartz, L.A., 1993. Language and modern human origins. Yearbook of Physical Anthropology 36, pp. $91-126$.

Sober, E., 1990. Anatomizing the rhinoceros. Behavioral and Brain Sciences 13, pp. $764-765$. 
Sober, E., (ed.), 1989. Conceptual Issues in Evolutionary Biology. MIT Press, Cambridge, Mass.

Sperber, D., 1990. The evolution of the language faculty: a paradox and its solution. Behavioral and Brain Sciences 13, pp. $756-758$.

Stam, J.H., 1976. Inquiries into the origin of language. The Fate of a Question. Harper and Row, New York, etc.

Sulloway, F.J., 1998. Darwinian virtues $(\approx$ Review of The Origin of Virtue: Human Instincts and the Evolution of Cooperation by M. Ridley, Viking). The New York Review of Books, April 9, 1998.

Symons, D., 1992. On the use and misuse of Darwinism in the study of behavior. In: Barkow, Cosmides, Tooby, (eds.), 1992, pp. $137-159$.

Tobias, P.V., 1996. The dating of linguistic beginnings. Behavioral and Brain Sciences 19, pp. $789-792$.

Whitcombe, E., 1995. Paleoneurology of language: Grounds for scepticism. Behavioral and Brain Sciences 18, pp. $204-205$.

Whitney, W.D., 1873. Oriental and Linguistic Studies, Vol.1. Scribner and Amnstrong, New York.

Wilkins, W., Wakefield, J., 1995. Brain evolution and neurolinguistic preconditions. Behavioral and Brain Sciences 18, $161-182,205-225$.

Worden, R., 1998. The evolution of language from social intelligence. In: Hurford, StuddertKennedy, Knight, (eds.), 1998, pp. 148 - 166.

Stellenbosch Papers in Linguistics, Vol. 32, 1999, 1-44

doi: $10.5774 / 32-0-51$ 